\title{
Biosynthesis and characterization of silver nanoparticles using Morus alba L. and their antioxidant activity
}

\author{
Asha Singh ${ }^{1 *}$, Sadhana Shrivastava ${ }^{1}$, Monika Sharma $^{2}$, Chandrakant Sharma $^{2}$ \\ and Sangeeta Shukla ${ }^{1}$ \\ ${ }^{1}$ UNESCO-Trace Element Satellite Centre, \\ School of Studies in Zoology, Jiwaji University, Gwalior (M.P.) \\ ${ }^{2}$ Department of Bioscience and Biotechnology, Banasthali University, Bansthali, Rajasthan \\ *Email: ashasgh87@gmail.com
}

Nanobiotechnology is a rapidly growing scientific field of producing and constructing devices utilizing nanosized paricles of about nanometer scale level (1 to $100 \mathrm{~nm}$ ). Now-a-days nanoparticles were potentially used in life sciences and human health care applications [1]. Silver nanoparticles are playing a major role in the field of biomedical nanotechnology and nanomedicine. In the present study silver nanoparticles were prepared using Morus alba leaf extract as reducing agent by a simple, cost-effective and eco-friendly process. The formation of synthesized nanoparticles were characterized by UVVisible spectrophotometer which showed absorbance peak in range of 620-646 nm (Figure 1).

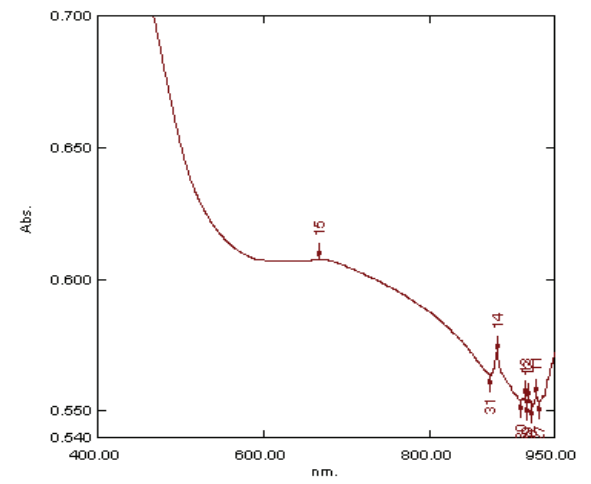

Figure 1: UV-Visible spectrum of synthesized silver nanoparticles

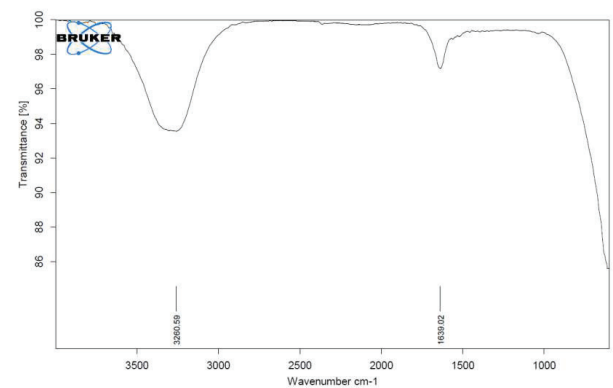

Figure 2: FTIR spectrum of synthesized silver nanoparticles

The functional groups present in plant extract were investigated by FTIR. Bioreduction were observed in the region of $400-4000 \mathrm{~cm}^{-1}$ with major peaks at
3260.59, that could be assigned to the $\mathrm{C}-\mathrm{H}$ stretching of carbonyl bond and $1639.02 \mathrm{~cm}^{-1}$ are secondary amine N-H stretch (Figure 2).

The zeta potential and particle size distribution of the silver nanoparticles were determined using MALVERN Dynamics Light Scattering (DLS) Instrument with zetasizer Version 7.11. A negative zeta potential value of $-13.3 \mathrm{mV}$ was observed which proved the stability of the silver nanoparticles and particle size of nanoparticles was observed within the range of 50-57 $\mathrm{nm}$ (figure 3).

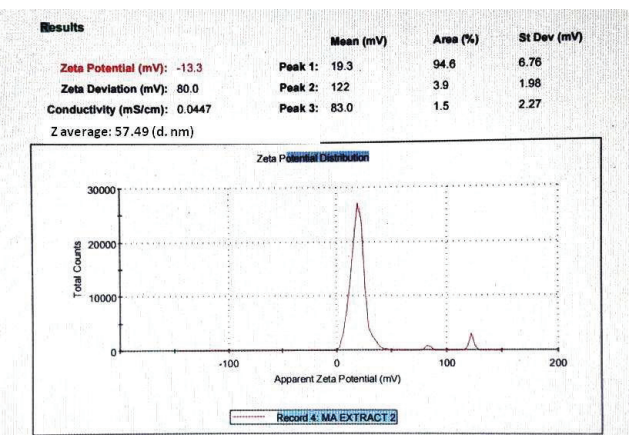

Figure 3: zeta potential of synthesized silver nanoparticles

The antioxidant activity of Morus alba derived AgNPs were checked using DPPH assay to quench the reactive oxygen species (ROS) which play important role in the development of cancer, cardiovascular diseases, inflammation and associate disorders [2]. Here the antioxidant activity of AgNPs was compared with standared ascorbic acid. Present results showed the antioxidant activity and $\mathrm{IC}_{50}$ of Morus alba mediated AgNPs were found in the range of $70-80 \%$ and $20-50 \mu \mathrm{g} / \mathrm{ml}$. These results indicate that Morus alba mediated AgNPs could work as potent antioxidant which might be due to capping of flavonoids present in plant extract.

\section{References}

1. Gnanajovitha, G. Paulkumar, K. Vanaja, M. Rajeshkumar, S. Malarkodi, C. Annadurai, G. and Kannan, C. Journal of Nanostructure in Chemistry, (2013), 3: 67.

2. Obrenovich, E.M. Li, Y. Parvathaneni, K. Yendluri, B. et al. Curr. Drug Targets: CNS Neurol Disord. (2011), 10: 192207. 